\title{
Tetanus and diphtheria immunity in adolescents from São Paulo, Brazil
}

\section{M.I.S. Dinelli ${ }^{1}$, M. Fisberg ${ }^{2}$ and M.I. de Moraes-Pinto ${ }^{1}$}

\author{
'Disciplina de Infectologia Pediátrica, Departamento de Pediatria, \\ ${ }^{2}$ Departamento de Pediatria, Centro de Atendimento e Apoio ao Adolescente, \\ Universidade Federal de São Paulo, São Paulo, SP, Brasil
}

\section{Correspondence \\ M.I. de Moraes-Pinto \\ Disciplina de Infectologia \\ Pediátrica \\ Departamento de Pediatria, UNIFESP \\ Rua Pedro de Toledo, 781, 9o andar \\ 04039-032 São Paulo, SP \\ Brasil \\ Fax: +55-11-5575.6928 \\ E-mail: m.isabelmp@uol.com.br}

Research supported by Fundo de

Auxílio ao Docente e ao Aluno

(FADA), Federal University of

São Paulo.

Publication supported by FAPESP.

........................

Received January 18, 2006 Accepted December 11, 2006

\begin{abstract}
Tetanus and diphtheria vaccines are of special concern in adolescents because boosters are necessary for adequate maintenance of protection and are often omitted. We assessed serum levels of tetanus and diphtheria antibodies in adolescents and their association with vaccination status. From May to October 2001, we evaluated the vaccination records of 208 adolescents aged 10 to 20 years in São Paulo, Brazil. Antibodies to tetanus and diphtheria were detected using double-antigen ELISA and vaccination records were analyzed according to the guidelines of the Brazilian National Immunization Program. All adolescents had received complete primary vaccinations against tetanus and diphtheria, but $23.1 \%$ of them had not received a booster dose in the last 10 years. All adolescents were immune to tetanus and $88.9 \%$ were fully protected (antibodies $\geq 0.1 \mathrm{IU} / \mathrm{mL}$ ). One individual $(0.5 \%)$ was non-immune to diphtheria and $86 \%$ were fully protected against the disease. Adolescents with up-to-date vaccination records had higher antibody levels than those with not up-to-date records for tetanus $(0.763$ vs $0.239 \mathrm{IU} / \mathrm{mL}, t$-test: $\mathrm{P}<0.0001)$ and diphtheria (0.366 vs $0.233 \mathrm{IU} / \mathrm{mL}, t$-test: $\mathrm{P}=0.014)$. Full immunity against tetanus (antibodies $\geq 0.1 \mathrm{IU} / \mathrm{mL}$ ) was higher among individuals with up-to-date vaccination $(93.1 \%)$ when compared to those with not upto-date records (75\%, Fisher's exact test: $\mathrm{P}=0.001)$. All adolescents had received basic immunization in childhood and were protected against tetanus and diphtheria. However, these data indicate that more emphasis should be placed on the tetanus-diphtheria booster in order to avoid a decay in antibody levels.
\end{abstract}

Age groups other than children are being targeted for vaccination worldwide (1). The priority of the National Immunization Program, when it was established in Brazil in 1973, was the vaccination of children (2). With the gradual elimination and control of many vaccine-preventable diseases in infancy, interest in immunization has been extended to other age groups, including ado-
Key words

- Vaccine

- Tetanus

- Diphtheria

- Adolescents

- Antitoxins

- Immunization lescents (2).

Tetanus and diphtheria vaccines are of special interest because boosters are necessary for the adequate maintenance of protection. Both diseases are presently under control in Brazil, with a large reduction in the number of cases and deaths over the last two decades (3). However, the epidemic of diphtheria that occurred during the 1990's in the 
Newly Independent States of the former Soviet Union, with a high proportion of cases amongst adolescents, highlights the necessity for a periodic surveillance of immunity against the disease $(4,5)$.

In the present study, we evaluated the diphtheria and tetanus vaccination and antibody levels against both diseases in adolescents. The protocol was approved by the Ethics Committee of the Federal University of São Paulo, São Paulo, SP, Brazil, and written informed consent was obtained from parents or guardians before enrollment.

From May to the beginning of October 2001, subjects aged 10 to 20 years were evaluated at the Adolescent Outpatient Clinic of the Federal University of São Paulo. We obtained $208(82.2 \%)$ vaccination records from a total of 253 recruited adolescents. Each volunteer participant completed a questionnaire with information on date of birth, age, sex, and previous immunizations and a blood sample was collected.

Vaccines and dates of administration were recorded and the immunization status was evaluated according to the Brazilian National Immunization Program, corresponding to the period when the individuals were immunized. The up-to-date immunization records, starting from early infancy, should have included at least three basic doses of diphtheria-tetanus-pertussis vaccine (DTP), a booster dose 6 months after the last dose, with subsequent tetanus-diphtheria (Td) booster doses every ten years.

Serum was separated and stored at $-80^{\circ} \mathrm{C}$ until tested for antibody levels at the Research Laboratory of the Division of Pediatric Infectious Diseases of the Federal University of São Paulo. Antibodies against diphtheria and tetanus were measured by an in-house doubleantigen ELISA developed by Kristiansen et al. (6). The double-antigen immunoassay for the detection and quantification of anti-tetanus and anti-diphtheria antibodies in serum showed good correlations with established toxin neutralizing assays $(R=0.960$ for tetanus, and $R=$
0.923 for diphtheria). Different from that observed when the indirect ELISA is used (which grossly overestimates sera with anti-tetanus and anti-diphtheria antibodies below $0.2 \mathrm{IU} /$ $\mathrm{mL}$ ), double-antigen ELISA has a good correlation also for low-titer sera $(<0.1 \mathrm{IU} / \mathrm{mL})(6)$. A high correlation of the results of doubleantigen ELISA and neutralization assays was also found in a study performed by the European Sero-Epidemiology Network (7).

For tetanus antibodies, a 96-microtiter plate (Nunc, Kamstrup, Denmark) was coated with $0.08 \mu \mathrm{g} / \mathrm{mL}$ of tetanus toxoid (Butantan Institute, São Paulo, SP, Brazil) diluted in $0.1 \mathrm{M}$ carbonate-bicarbonate buffer, $\mathrm{pH}$ 9.6, and was incubated overnight at $4^{\circ} \mathrm{C}$. Two-fold serial dilutions of serum samples and of reference tetanus serum (in-house standard calibrated against tetanus antitoxin human immunoglobulin NIBSC reagent 1976 (76/589), Potters Bar, UK) in dilution buffer (10 mM PBS, $\mathrm{pH}$ $7.2,1 \%$ Triton $\mathrm{X}-100$ ) with $1 \%$ bovine serum albumin (Amersham, San Francisco, CA, USA) were added to the plate and incubated for $1 \mathrm{~h}$ at $37^{\circ} \mathrm{C}$. Biotin-labeled tetanus toxoid in dilution buffer was then added to the plate and incubated for $1 \mathrm{~h}$ at $37^{\circ} \mathrm{C}$. Streptavidinalkaline phosphatase conjugate (Zymed, San Francisco, CA, USA) in dilution buffer was incubated for $1 \mathrm{~h}$ at $37^{\circ} \mathrm{C}$. In the next step, $p$ nitrophenyl-phosphate (Sigma, St. Louis, MO, USA) in $1 \mathrm{M}$ diethanolamine, $5 \mathrm{mM}$ magnesium chloride buffer, $\mathrm{pH} 9.8$, was used as a substrate and absorbance was read at 405 and $630 \mathrm{~nm}$ with an immunoreader ELX-800 (BioTek Instruments, Winooski, VT, USA). The plate was washed five times in dilution buffer between steps.

The same method was applied for the diphtheria antibodies, with some modifications: $0.05 \mu \mathrm{g} / \mathrm{mL}$ diphtheria toxoid (Butantan Institute), reference diphtheria serum (inhouse standard calibrated against diphtheria antitoxin human serum 91/534, NIBSC reagent) and biotin-labeled diphtheria toxoid were used as substitutes for the corresponding tetanus reagents. 
Tetanus and diphtheria antibodies are reported as IU/mL using the curve comparison method to transform absorbance to concentration units.

Adolescents were classified into categories of immunity to tetanus and diphtheria according to internationally accepted criteria (7-10). Individuals with antibody concentrations of $0.1 \mathrm{IU} / \mathrm{mL}$ or more were considered to be fully protected and individuals with levels below $0.01 \mathrm{IU} / \mathrm{mL}$ were considered to be non-immune. Those with antibody levels of $0.01 \mathrm{IU} / \mathrm{mL}$ or higher and lower than $0.1 \mathrm{IU} / \mathrm{mL}$ were classified as having basic protection. Antibody concentrations $\geq 0.01$ and $<0.1 \mathrm{IU} / \mathrm{mL}$ protect most individuals against the disease, but are usually considered to represent short-term protection. Protection against the disease also depends on the general immune status of the individual, the dose of bacilli and the amount of toxin produced $(8,9)$.

Statistical analysis was carried out using the MINITAB 10 and STATA 7.0 programs. Geometric means were produced from raw data. Serum antibody levels were compared between groups by the Student $t$-test. Values were submitted to logarithmic transformation before analysis due to non-normal distribution. The chi-square test and the Fisher exact test were employed to evaluate possible association between groups and variables.

Of the 208 adolescents who had immunization cards, $61.5 \%$ were females and $38.5 \%$, males. Age ranged from 10.4 to 19.9 years (mean: 14.7 years; median: 14.5 years). According to the National Immunization Program schedule, 160 of them $(76.9 \%)$ had an up-to-date card and 48 (23.1\%) had not upto-date records. Of the 48 subjects with not up-to-date immunization records, two had not received the DTP booster or the subsequent $\mathrm{Td}$ booster. $\mathrm{Td}$ booster records were missing from all of the other 46 cards.

All adolescents were immune to tetanus: $185(88.9 \%)$ were classified as having full protection and $23(11.1 \%)$ as having basic protection. For diphtheria, only 1 adolescent $(0.5 \%)$ was non-immune, $28(13.5 \%)$ had basic protection, and $179(86.0 \%)$ were fully protected.

We analyzed the relationship between categories of immunity and immunization status. For tetanus, $93.1 \%$ of the adolescents with up-to-date immunization were fully protected; in contrast, those with not up-to-date cards were fully protected in $75.0 \%$ of cases (Fisher's exact test: $\mathrm{P}=0.001$; Figure 1 ).

For diphtheria, no statistical difference was found between subjects with up-to-date and not up-to-date immunization records (Fisher's exact test: $\mathrm{P}=0.716$ ). Eighty-five percent of adolescents with up-to-date immunization cards were fully protected, $14.4 \%$ had basic protection and one person $(0.6 \%)$ was non-immune to diphtheria; $89.6 \%$ of adolescents with not up-to-date records had full protection and $10.4 \%$ had basic protection against diphtheria (Figure 1).

Adolescents with up-to-date tetanus

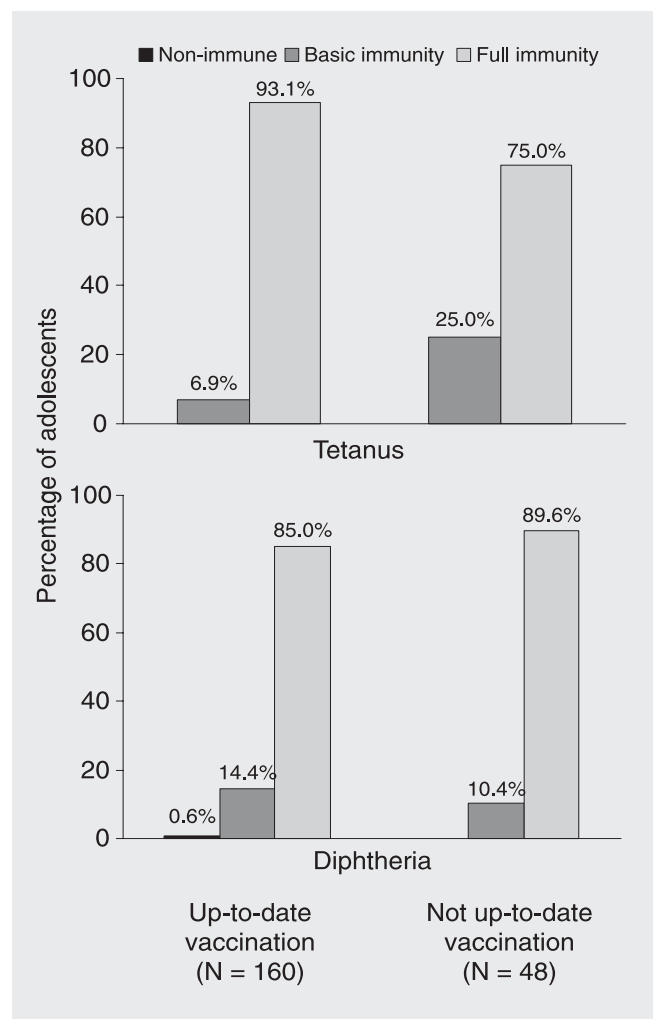

Figure 1. Immunity to tetanus and diphtheria in adolescents as a function of vaccination status. 
records had higher geometric mean antibody levels $(0.763 \mathrm{IU} / \mathrm{mL}, 95 \%$ confidence interval - CI: 0.595-0.979) than those with not up-to-date records $(0.239 \mathrm{IU} / \mathrm{mL}, 95 \%$ CI: 0.172-0.332; Student $t$-test: $\mathrm{P}<0.0001$; Figure 2).

Similarly, diphtheria geometric mean antibody levels were higher in adolescents with up-to-date immunization $(0.366 \mathrm{IU} / \mathrm{mL}$, 95\% CI: 0.295-0.454) than in those without up-to-date immunization $(0.233 \mathrm{IU} / \mathrm{mL}, 95 \%$ CI: 0.174-0.311; Student $t$-test: $\mathrm{P}=0.014$; Figure 2).

It is important to point out that geometric mean tetanus antibody levels were significantly higher than diphtheria antibodies (0.584 vs $0.330 \mathrm{IU} / \mathrm{mL}$, respectively; paired Student $t$-test: $\mathrm{P}=0.0001)$. No gender differences were noted for levels of tetanus antibodies (males: 0.539, females: 0.614; $t$-test, $\mathrm{P}=0.556$ ) or for diphtheria antibodies (males: 0.323 , females: 0.334 ; $t$-test, $\mathrm{P}=0.873$ ). However, adolescents older than 15 years had higher antibody levels than those younger than 15 for tetanus $(0.972$ vs 0.390 , respec-

Figure 2. Logarithmic scale of tetanus and diphtheria antibody levels in adolescents with up-todate and not up-to-date immunization. Horizontal lines in box plots indicate the 25th, 50th, and 75th percentiles; top and bottom vertical lines mark extreme values and, when present, asterisks represent outlying values. $P$ values compare antibody levels for tetanus and diphtheria in groups with up-to-date to not upto-date immunization (Student $t$ test).

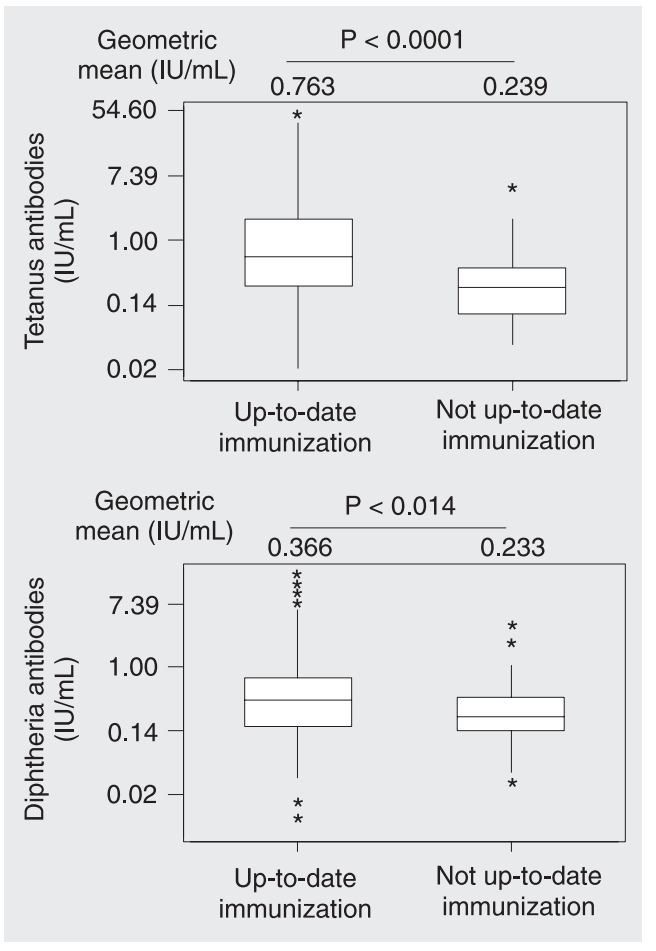

tively; $t$-test, $\mathrm{P}<0.001)$ and diphtheria $(0.477$ vs 0.246 , respectively; $t$-test, $\mathrm{P}=0.003$ ), probably reflecting the effect of the $\mathrm{Td}$ booster dose.

Awareness of the need to vaccinate adolescents is increasing (1). Many studies have shown that immunity to diseases that need booster vaccine doses starts to decline in adolescence and early adulthood (11-14).

In the present study, we have shown that more than $82 \%$ of the adolescents surveyed had kept their vaccination cards. Pachon et al. (12) have also found that among Spanish children and adolescents, failure to produce vaccination cards was more prevalent in the 10-12-year age group than in the 2-10-year age group. In Greece, health charts were obtained from $79 \%$ of the individuals aged 15-19 years (13).

Most of the adolescents who produced vaccination cards were up-to-date, but $23.1 \%$ had missed tetanus and diphtheria booster doses. Lower statistics regarding booster doses have been recorded in other countries. In Spain, while primary vaccine series coverage was high, 62 to $83 \%$ of adolescents had not received a tetanus booster at 14 years of age (12). In Greece, the vaccination rate for adolescents was $65 \%$ for tetanus and only $54.4 \%$ for diphtheria (13). Likewise, in Berlin only 59\% of 2079 blood donors reported that they had been vaccinated against tetanus in the previous 10 years. For diphtheria, the rate was even lower, $17 \%$ (10). According to a national survey in the United States, $65 \%$ of individuals aged 18 to 49 years reported having been immunized against tetanus in the last ten years, and the proportion decreased to $40 \%$ among those aged 65 years or more (15).

The analysis of tetanus and diphtheria antibodies in adolescents mirrored their vaccination status as assessed by their immunization records. Those with up-to-date vaccinations against tetanus and diphtheria had higher antibody concentrations. When adolescents were divided into categories of im- 
munity, more individuals with up-to-date vaccination cards were found to be fully protected against tetanus. These findings confirm that, as age progresses, a person's susceptibility to tetanus and diphtheria increases if booster doses are omitted $(8,9,14,16-19)$.

As also observed in other countries, many Brazilian adolescents from São Paulo, although fully vaccinated during infancy, tend to miss their Td vaccine booster doses (12, 13), leading to a clear decay in diphtheria and tetanus antibody levels.

Because tetanus and diphtheria vaccines have excellent efficacy records $(8,9)$, efforts should be directed at adolescents and parents to encourage a better vaccination coverage for this age group.

\section{References}

1. Plotkin SA. Vaccines: past, present and future. Nat Med 2005; 11 (Suppl 4): S5-S11.

2. Brazilian Ministry of Health. National Immunization Program 30 years. http://portal.saude.gov.br/portal/arquivos/pdf/livro_30_anos_ pni.pdf. Accessed September 21, 2005.

3. Brazilian Ministry of Health. State of art of prevention and control of transmissible diseases in Brazil. http://portal.saude.gov.br/portal/ arquivos/pdf/graficos_dnc_19_08_04.pdf. Accessed September 21, 2005.

4. Galazka A. The changing epidemiology of diphtheria in the vaccine era. J Infect Dis 2000; 181 (Suppl 1): S2-S9.

5. Dittmann S, Wharton M, Vitek C, Ciotti M, Galazka A, Guichard S, et al. Successful control of epidemic diphtheria in the states of the Former Union of Soviet Socialist Republics: lessons learned. $J$ Infect Dis 2000; 181 (Suppl 1): S10-S22.

6. Kristiansen M, Aggerbeck H, Heron I. Improved ELISA for determination of anti-diphtheria and/or anti-tetanus antitoxin antibodies in sera. APMIS 1997; 105: 843-853.

7. von Hunolstein $C$, Aggerbeck $H$, Andrews N, Berbers G, FievetGroyne F, Maple PA, et al. European sero-epidemiology network: standardisation of the results of diphtheria antitoxin assays. Vaccine 2000; 18: 3287-3296.

8. Galazka AM. The immunological basis for immunization series. Module 2: diphtheria. Geneva: World Health Organization; 1993.

9. Galazka AM. The immunological basis for immunization series. Module 3: tetanus. Geneva: World Health Organization; 1993.

10. Stark K, Schonfeld C, Barg J, Molz B, Vornwald A, Bienzle U. Seroprevalence and determinants of diphtheria, tetanus and poliomyelitis antibodies among adults in Berlin, Germany. Vaccine 1999;
17: 844-850.

11. Lambert PH, Liu M, Siegrist CA. Can successful vaccines teach us how to induce efficient protective immune responses? Nat Med 2005; 11: S54-S62.

12. Pachon I, Amela C, de Ory F. Age-specific seroprevalence of poliomyelitis, diphtheria and tetanus antibodies in Spain. Epidemiol Infect 2002; 129: 535-541.

13. Bitsori M, Ntokos M, Kontarakis N, Sianava O, Ntouros T, Galanakis E. Vaccination coverage among adolescents in certain provinces of Greece. Acta Paediatr 2005; 94: 1122-1125.

14. McQuillan GM, Kruszon-Moran D, Deforest A, Chu SY, Wharton M. Serologic immunity to diphtheria and tetanus in the United States. Ann Intern Med 2002; 136: 660-666.

15. Singleton JA, Greby SM, Wooten KG, Walker FJ, Strikas R. Influenza, pneumococcal, and tetanus toxoid vaccination of adults United States, 1993-7. MMWR CDC Surveill Summ 2000; 49: 39-62.

16. Damasco PV, Pimenta FP, Filardy AA, Brito SM, Andrade AF, Lopes GS, et al. Prevalence of $\lg$ diphtheria antitoxin in blood donors in Rio de Janeiro. Epidemiol Infect 2005; 133: 911-914.

17. Edmunds WJ, Pebody RG, Aggerback H, Baron S, Berbers G, Conyn-van Spaendonck MA, et al. The sero-epidemiology of diphtheria in Western Europe. ESEN Project. European Sero-Epidemiology Network. Epidemiol Infect 2000; 125: 113-125.

18. Maple PA, Jones CS, Wall EC, Vyseb A, Edmunds WJ, Andrews NJ, et al. Immunity to diphtheria and tetanus in England and Wales. Vaccine 2000; 19: 167-173.

19. Redwan EM, El-Awady MK. Status of diphtheria immunity in the Egyptian population. Ann Trop Med Parasitol 2005; 99: 93-99. 